\title{
Cross-cultural Frictions in Information System Management: Research Perspectives on ERP Implementation Misfits in Thailand
}

\author{
Régis Meissonier ${ }^{1}$, Emmanuel Houzé $^{2} \&$ Véronique Bessière ${ }^{2}$ \\ ${ }^{1}$ Université Picardie Jules Verne, France \\ ${ }^{2}$ IAE, Université Montpellier 2, France \\ Correspondence: Régis Meissonier, Professeur des Universités, Université Picardie Jules Verne, France. E-mail: \\ regis.meissonier@univ-montp2.fr
}

Received: May 25, 2012

doi:10.5539/ibr.v6n2p150

\begin{abstract}
Today, enterprise systems (ERP) are considered as ones of most impacting IT on business and decision processes because of their cross-functional perspective and readiness to change. As a consequence, a lack of "organisational fit" is observed as the main failure cause of ERP implementation. A lot of acts of resistance are observed as being task oriented and related to the non-appropriateness of IT that users have to cope with. Existing literature provides practical knowledge about conflict types and conflict management styles related to process and task misalignment between ERP and corporation needs. However, few researches were made about cultural misfits. Indeed, when an organisation is composed of several sub-cultures, the use of ERP can be problematic because mandating one epistemological position through the software design is based on "best practices". Subsidiaries of multinational corporations have their own subculture varying in their national cultural content. Value conflicts may arise from inconsistency between cultural principles of users or groups of users and the perceived underlying strategic objectives assigned to IT implementation. Expending the classical Schein triadic model with the concept of "cultural friction", this paper provides a critical analysis of cultural dimension misalignment between ERP standard processes and Thai managerial culture. Key theoretic discussed dimensions are Ego orientation ("Kreng Jai") and, Social orientation ("Bunkhun"). The article concludes that failing projects are more about the way ERP ought to be implemented than about the system itself.
\end{abstract}

Keywords: ERP, Information Systems, Thai culture, western culture, cultural misfits, research perspectives

\section{Introduction}

A large part of literature defines Information Systems (IS) project achievement as a 'fit' (Strong \& Volkoff, 2010) between the enterprise and the Information Technology (IT) prerequisites in terms of users readiness to change of system (Kwahk \& Lee 2008; Walczuch et al., 2007), new professional skills required (Besson \& Rowe, 2001; Newman \& Westrup, 2005), underlying managerial policies (Lim et al., 2005), organisational changes (Markus, Tanis, et al., 2000; McAfee, 2007; Robey et al., 2002), power redistribution (Hart \& Saunders, 1997; Jasperson et al., 2002; Markus, 1983), and organisational cultures (Kohli \& Kettinger, 2004; Leidner \& Kayworth, 2006; Wagner \& Newell, 2004). Alignment misfits and resistances toward IT have largely been studied from an intra-organisational perspective. However, few studies analysed how an IT project can represent a western cultural artefact dissonance with local national culture in the case of cross-cultural IT implementation.

This research question is all the more important that enterprise systems (ERP) represent a major challenge for multi-national corporations aiming to implement an integrated information system in their subsidiaries located in foreign countries. In the present time, ERP expenses represent the most important IS budget of large corporations. However, they are considered to be the most impacting IT (Lee \& Myers, 2004) because mandating cross-functional business processes based on "best practices" instead than designed from expressed user needs (Markus, 2000). In other words, ERP systems impose one epistemological position (Wagner \& Newell, 2004) to firms and their subunits about the way their activity must be proceed and their strategical decisions made. Then, such IS projects are likely to raise cultural issues associated with the underlying business globalisation strategy.

The objective of this article is to provide a literature review about national cultural conflicts in the case of ERP implementation. An appropriate way to deduce research perspectives on this topic, is to voluntary focusing the 
review on a country having a contrasted business culture to the western one, while hosting a lot of subsidiaries of American or European companies. This is why we chose Thailand because of its culture embedded with Buddhist philosophy and because being a manufacturing centre for emblematic American and European industries.

The rest of the article is structured as follow. Expending Schein triadic model (1984) with the concept of "cultural friction" (Shenkar et al., 2008), the first part provides a theoretic-set to apprehend cultural dimension misalignment between ERP and Thai culture. Key discussed dimensions in the second part are Ego orientation ("Kreng Jai") and Social orientation ("Bunkhun"). Research perspectives are put forward in terms of project management. The article concludes that failing projects are more about the way ERP ought to be implemented than about the system itself.

\section{IT as Cultural Artefact}

A huge quantity of definitions and characterisations exists in the literature about culture, and probably a first challenge for an article on this topic is giving a satisfactory description. A large part of cross-cultural research relies on Hofstede considering culture as a collective mental programme shared among members of a country, a region, or a group; and unshared with not members (1991). With this theoretical lens, analysis often takes the form of descriptive comparisons of national cultures based on pre-defined cultural dimensions of Hofstede model. This is gives some interpretation of international projects failures (subsidiaries implementations, exportations, strategic alliances, etc.) because fundamental concepts (time, power, risk, success, etc.) being perceived differently across partner countries. However, this theoretical basis fails into going beyond cultural dissonance and providing an understanding about how reaching a cross-cultural fit. In this article we use an approach more focused in the way culture "works" and may evolve over time.

According to the anthropologist perspective of Bourdieu, culture is a double process. First, culture shapes the way persons behave and give them a predisposition in terms of expected way of being (structuralist approach). However, one cannot simply consider organisation culture as a social characteristic of the enterprise. The way individual behave also influence and structure the organisational culture. Then, the culture of an organisation is constructed by individual according to their personal culture (constructionist approach). The interest of Bourdieu theory is putting forward this twofold approach as not exclusive and being actually two sides of a same social process. In other words, organisational culture is a construct.

This construct represents a framework embedded in managerial processes, practices and beliefs. It is considered as a challenge to allow corporations to develop group identity (Handley et al., 2006; Wenger et al., 2002), intellectual asset and knowledge creation (Alavi \& Leidner, 2001), and to sustain competitive advantage (Alavi et al., 2005; Drucker, 1998; Teece, 2003). According to Schein (1984), organisation culture is aggregated into three different categories: artefacts, values and basic assumptions.

Artefacts are the most visible manifestations of organisational culture. Ceremony, architecture, technology, office layout, behavioural patterns (dresses, jargons, etc.), business stories, etc., represent artefacts whom signification is to create and maintain the identity of the group. Like rites and symbols, their objective is to create a visible distinction between persons who are in conformity with social expectations of the group and the ones who are not. If artefacts are the most visible part of organisational culture, they are sometimes hard to decipher by themselves because related to underlying values.

Values in an organisation are the governing professional rules. They represent the official philosophy of the firm. Values are general feelings, more emotional than rational, reflecting the preferences in terms of expected behaviours in specific contexts. Schein distinguishes two types of values: declared values (like chart and discourses) and operational values which are more implicit and sustain decisions to be made, strategy and functional modes. Some mantra like "Business first" or "Family first" are illustrations of values on behalf of which individual or collective decisions are expected to be made. This cultural category is the most studied one, however by itself if fails disclosing the reasons why the organisation developed these values instead of other ones. To do so, it is necessary to identify basic assumptions.

Basic assumptions are the underlying reasons of the values shared in the organisation. According to Schein, they are unconscious beliefs that individuals have toward human nature, relationships toward the environment, time, space, etc. In this sense, basic assumptions are less debatable than values can be because being related to the fundamental cognitive structure that people use to make sense of the situations and event they have to cope with over time (Leidner \& Kayworth, 2006; Van Maanen \& Barley, 1985).

If one accepts Schein triadic model, IT are supposed to be visible artefacts instrumenting processes designed 
from values and basic assumptions of the organisation. However most of IT implemented in corporations nowadays are not exclusively tailored to organisation needs and cultural specificities. In other words, one can assume IT artefacts to be dissonant with existing cultural values and basic assumptions of the firm.

Information systems research investigated the effects of both national and organisational culture on project development (Dube, 1998; Ngwenyama \& Nielsen, 2003; Robey \& Markus 1984), IT adoption (El Sawy, 1985; Hoffman, 2000; Jarvenpaa \& Leidner, 1998; Karahanna et al., 2005), IT diffusion and acceptance (Straub, 1994; Straub et al., 1997), IT use (Kappos \& Rivard, 2008; Vance et al., 2008) and IT performance (Gold et al., 2001; Kanungo et al., 2001; Weber \& Pliskin, 1996). However, these researches tend to consider culture as a contextual and static characteristic of the project whereas organisational culture is conversely shaped by IT (Walsham, 2002). In other words, organisational culture ought to be more considered as a process than as established firm properties. This distinction is crucial to evacuate any static interpretations of cultural misfit. Indeed, a large part of the literature analysed cultures with a positivist posture conferring them ontological values to their impacts or their differences. The most popular metaphor used to express cultural misfits in international management research is "cultural distance". This concept actually illustrates a geographic perspective implying a metric state of the difference level between two supposed steady entities. Shenkar et al. (2008) proposed to use the "friction" metaphor instead of the "distance" one to represent how cultural asymmetries are also a configuration allowing persons to resist, bargain, and learn.

In this article, we propose to expand this approach with the triadic of Schein. We consider cultural misfit in Information Systems projects as value conflict between IT artefact and organisation basic assumptions. Like Schein we consider value as the interplay of artefacts and basic assumptions. The difference with the author is artefact being a vector of a foreign culture distillation in the organisation. The concept of "frictions" must here be understood in the sense of Shenkar et al. as interactions between persons to make sense of cultural differences. Decisions made about IT implementation without consensus are likely to involve systems' usages very different from the ones expected by managers (Soh \& Kien Sia, 2004). Thus, "cultural frictions" can be interpreted as appeals for managerial rectifications like recognizing different managerial philosophies in the design of IT to implement.

IT to be implemented can be perceived by employees as inconsistent with existing organisational culture (Markus \& Robey, 1983) when they impose a unique managerial paradigm (Wagner \& Newell, 2004). ERP is one of the most representative examples because editors designing business processes from what they consider as the "best" managerial practices observed in one or several major industries of the business sector. In terms of flexibility these software packages are promoted as being configurable to match a diversity of business contexts. Any module a firm decide to implement is parametrized according to its preferences. However, the way the processes are designed is not supposed to be modified and firms are encouraged into a "vanilla implementation" to capture "best practices" experienced by leader competitors. As a consequence, most of ERP projects involve a reengineering of existing business processes. They are well-known conflict drivers because of "ready-to-use module" imposed on employees without too much consideration of firm specificities (Davenport, 1998; Lim et al., 2005; Markus, Axline, et al., 2000). This type of misalignment is all the more important, as problems in Management Information Systems (MIS) are more about the ability of users to understand how they must carry out their new tasks than about the ability of the firm to manage change (Robey et al., 2002). As a consequence, resistances expressed toward the system can hide cultural oriented conflict likely to jeopardize project achievement (Meissonier \& Houzé, 2010).

\section{Research Perspectives about ERP vs Thai Culture}

Most of benchmarked corporations from which ERP standard modules are designed are worldwide leaders of their business sector. Most of them are American or European companies successfully applying modern and sophisticated managerial principles inherited from the western business culture. Despite their potential effectiveness, they only are one way of doing business according to fundamental principles related to norms, values and assumption about what is "good" or "bad", what performance is, relations to the others, time perception, etc.

As IT artefacts of the western business philosophy, ERP projects can be conflictual with basic assumptions of foreign cultures. Thailand is an Asian country having suitable characteristics to conduct this analysis. Firstly, compared to other industrialized Asian countries like China, Vietnam, Japan, Thailand is one of the few having a homogeneous national culture: Buddhism. Muslin and catholic communities only represent respectively 4,6\% and $0,5 \%$ of the population. Buddhism exerts an important influence on Thai people in the daily life and the way they behave both in private and professional context. This allows a holistic cross-cultural analysis. Secondly, 
historically, Thailand is the only South East Asian civilisation never colonized by American or European countries. It has been less influenced than neighbour countries by western culture. Thirdly, buddhism is one of the most contrasted foreign cultures to the western ones more influenced by protestant and catholic religions. Fourthly, Since 1990s, Thai culture has been evolving because of globalisation and economic growth. New transitional values imported from western culture (individualistic performance, material and ownership as sign of success, etc.) are grudgingly infused (Klausner, 1998; Niffenegger et al., 2006, p. 407). As a consequence, Thai people positively consider Information Technology implementation as a symbol of modernism and success for the country (Vatanasakdagul et al., 2010). So, we cannot assume a sort of national aversion about ERP systems themselves preventing any possible cultural fit. Fifty, Thailand represents a key hosting platform for American and European multinational companies that implemented subsidiaries to sustain exportations in Asia (see for instance: Ford and BMW in automobile sector; Procter \& Gamble and Nestlé in food sector; Coca-Cola and Heineken in drink sector; Western Digital and Thomson in IT sector; Dow Chemical and Rhodia in chemical sector, Weatherford and Total in energy sector, etc.). Such worldwide industries are challenging for a globalisation of their activity and process standardisation of their sites and subsidiaries network. For instance, Ford has been standardizing operation management in new emerging countries with QAD MFG/PRO solution. Since 1996, the car manufacturer has been implementing the ERP in its sites of India, Russia, Philippines, Shangaï, Viet Nam and Thailand. Ford Motor of Bangkok employs more than 100 QAD users to daily synchronized operations and financial reporting with the head-office. For editors and project managers, Thailand represents one of the several foreign sites where ERP must be implemented; and for academic an interesting field of research about potential cross-cultural misfits.

Our analysis does not aim to cover all cultural characteristics that should be taken into account in cross-cultural projects management with Thailand. A lot of them have been largely discussed in prior research (Hofstede \& Bond, 1988; Komin, 1990; Niffenegger et al., 2006) which highlighted underlying religious and philosophical principles as perspective research review, the article focuses on cultural misfits associated with ERP project management specificities that have not been discussed in the literature so far. Based on Joungtrakul $(2004,2009)$ research, we articulate our analysis (see Figure 1) in function of two main concerned philosophical aspects of Thai culture. The first one ("Kreng Jai") is ego orientated and the second one ("Bunkhun") is social oriented.

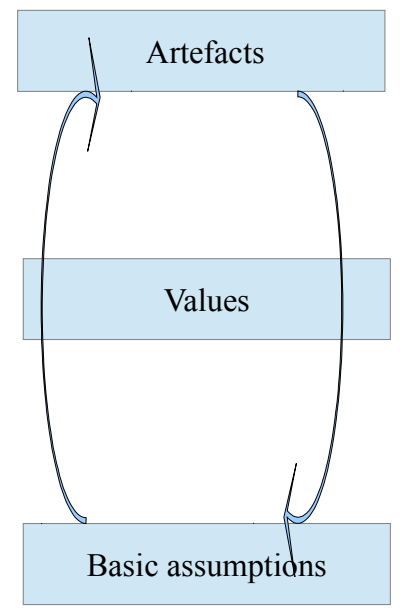

ERP as Symbol of western managerial practices

Potential cultural 'frictions' about:

- conflict and change management

- power delegation

- involvement of seniors

- partnership building

Ego orientation ("Kreng Jai")

Social orientation ("Bunkhun")

Figure 1. ERP as cultural friction artefact to Thai culture

\subsection{Ego Orientation ("Kreng Jai")}

Ego orientation can be considered as the most influencing cultural characteristic on behavioural patterns of Thai people (Komin, 1990). "Kreng Jai" is often translated as "deferential heart" and implies permanent respectful and politeness interactions. Whenever a problem appears, the challenge for Thai persons is "saving the face". A dispute represents a frustrating situation for Thai to be absolutely avoided. If it raises anyway, the situation tends to create an antecedent very difficult to recover. Indeed, with difference to western culture, Thai people do not make real difference between ideas defended by a person and the person himself. In other words, there are no fundamental differences between addressing criticisms to the ideas defended by a Thai and addressing a value judgement of the person him/herself. 
This point turns out to have strong implications in the way ERP implementation is normally carried out. Indeed while conflict is considered as having to be avoided (Markus, 1983) and actively managed in IS projects (Barki \& Hartwick, 2001), research considers ERP raise unpredicted organisational changes (some of them can be related to cultural frictions) and successful mandatory IT implementations depends more on the ability to manage a "shakedown phase" (Markus, Tanis, et al., 2000) than on the ability to carefully anticipate and prevent all issues. As a consequence, users are forced, during post-adoption phase' to develop adaptive strategies (Beaudry \& Pinsonneault, 2005) and a large part of conflicts are observed as related to the non appropriateness of IT users have to cope with. In western managerial culture, conflict is not perceived as being automatically dysfunctional or disruptive both form an organisational and individual point of view. During the 1920s' social and economic crisis period, Mary Parker Follett was a precursor of this way of thinking and presented conflict as a normal process of organisations. According to her, it is a permanent reality of social life not to be avoided but, at the contrary, to be used by managers. In western countries, having organisations with absolutely no resistances would mean employees would accept all changes, including those detrimental to the organisation effectiveness (J. Ford et al., 2008). Conflicts can "clear the air" (Coser, 1956), and maintain relationships under conditions of stress, and thereby prevent group dissolution. In IT projects, by considering conflict as negative for the organisation, managers can disregard its potential contribution to the change and implementation process. In this sense, conflict can even be considered as part of the IS design (Meissonier \& Houzé, 2010).

Conversely, in a Thai cultural context, ERP project managers cannot rely on hypothetical positive effects of conflictual situations to reach a similar consensual arrangement. In mandatory IT implementation, one can assume such "constructive conflicts" not likely to raise because corresponding for Thai people as a dishonourable contest of the hierarchy. Specific cultural values worth to be developed emphasizing on conflict prevention since pre-implantation phase. Inducing a consensual design of the project before IT decision implementation being made can be considered as a mark of project legitimacy supporting post-adoption.

Proposition 1.1: in Thailand, ERP project achievement depends more on the ability to manage resistances in pre-implementation phase than in post-implementation phase.

The concept of "Kreng Jai" applied in a business sense also deals with the horizon of projects. Social and interpersonal harmony, and its consequence with conflict avoidance as seen just before, implies a longer-term orientation. Business relationship implies mutual trust and personal contacts. The objective is to build a sustainable and comfortable relation for each part. Its means that the need for quick results will not be so relevant as in western culture. It is deeply related with conflict avoidance and proposition 1: the pre-implementation phase will take time because time is necessary to "carefully anticipate and prevent all issues" (quoted from the text above). More generally, decision- making behaviour is more reflective in eastern culture (Jehn \& Weigelt, 2001)

Proposition 1.2: In Thailand, ERP project pre-implementation phase takes time and is not speed-oriented.

These research propositions point out a paradox: while most or ERP implementations are mandatory projects, how can a consensus be obtained without conflict? The second dimension of Thai culture discussed provides other research perspectives in this sense.

\subsection{Social Orientation ("Bunkhun")}

The concept of "Bunkhun" or "Katanyu" is often translated as "gratefulness". It corresponds to the respect and thankfulness Thai people must have toward the ones who provided their help. Family members, professors, buddhist monks, but also elders ones represent the "keystones of the unfailing moral order" (Joungtrakul, 2004). One of the differences with western culture is this mark of respect expressed with rituals. For example, each year, schools organise the "Wai khru" as honouring ceremony devoted to teachers. A buddhist prayer opens the ritual and is followed with student songs, recitations, flowers, candles and gift offerings. Thai boxing masters are also honoured by the "Wai khru ram muai" ceremony, a traditional ritual mixing dance and fights. In the daily life, the "Bunkhun" also determines attitude and face expressions of people depending who they are talking to. For example, when somebody is thanked for his help, he adopts a face-threatening if one owes gratitude ("Phuu mee phrakun" status). This is a way to express that the "thankee" does not consider the "thanker" as indebted. Actually relationships are ruled by this social categorization. It includes adult over children, teachers over students, elders over younger ones, militaries over civilians, etc. Depending their age, social rank, power level, etc. persons are identified as "big people" ("Phu Yai") or "little people" ("Phu Noi"). The first time a Thai meets somebody else he may ask some questions to assess is social rank and to know how he must behaves.

Daily relationships in professional contexts are also governed by these symbolistic rules. As representatives of power and professional experience, hierarchical superiors and senior employees are "Phu Yai" and worthy of a 
similar mark of gratitude. Thai management style is family-oriented. Superiors feel forced to operate as "fathers" and taking care of their workers and employees (Komin, 1990; Niffenegger et al., 2006). This social status does not mean a hierarchical distance in the sense of western culture as observed by Hofstede. Indeed, there are sort of cultural mutual obligations between the two categories. "Phu Yai" must offer assistance and take care of the "Phu Noi" they are regularly in touch with in exchange of their mark of respect.

One of the commonly acknowledge success factor for ERP project is the ability of the CIO to implicate "key users" since the project beginning (Davenport, 1998; Markus, Axline, et al., 2000). This idea about users implication challenge takes often the form of a ritual in information system development (Hirschheim \& Newman, 1991). Key users are normally considered as the most able to endorse change required by the IS project. An ERP is synonym of radical organisational modification questioning the relevance of prior processes and practices. Like with reengineering project (BPR), and transformation strategies, the path-dependency of the firm is considered as likely to jeopardize the readiness of the firm to change absorption. If one has to depict the ideal "key user prototype" one would represents him as an enough experienced young employee or executive in line with the way the organisation is aimed to evolve by the CEO. The symbolistic legitimacy of key users is more associated with the future they are supposed to represent than with the past of the corporation.

This symbolistic value addressed to key users cannot ensure their legitimacy in Thailand corporations. As a ritual of IS design, key users implications in Thai culture oughts probably to enrol employees in line with Bunkhun principle: senior users who give a legitimacy to the project because representing the image of the firm history and continuation. Time perception in Thailand culture is different than the one of western culture: the past, the present and the future are more inter-related in a long-term orientation. Indeed, future in Thailand does not mean a rapid change having to be done by fixed deadlines. Efforts must be done to build long-term relationships and perspectives as essential characteristics of success and performance. Patience and persistence are crucial qualities employees have to develop. Senior employees can represent time experience and wisdom required for this quest.

At the same time, one cannot expect same rule played by key users in a western cultural context than the one played in Thai cultural context. A case-study research conducted in a Thailand in an engineering project (Corbitt et al., 2004, p. 77), revealed because hierarchical cultural distance, team members tended automatically to rely to superiors for any risky decision to be made. There was an "upward delegation" tendency different than the one expected in western culture as a user delegation of the IS design. It may be hazardous supposing Thai "key users" having same disposal to decide of the suitability of the system to be implemented on behalf of all users. This is related to "Thai culture's high uncertainty avoidance" (Niffenegger et al., 2006, p.411, following Hofstede, 1991). The legitimacy of key users and the role of "elders" (hierarchical superiors, senior employees) can be seen as a way to manage uncertainty. The role of devotion and trust in buddhist culture, the strong sense of hierarchy allows people to feel responsibility as personal, namely placed directly on the individual (Joungtrakul, 2006). The literature documents that the degree of uncertainty avoidance in IT adoption can lead to a reduction of confidence, in particular in web transactions (Pavlou, 2002; Ratanasignam \& Phan, 2003).

This analysis and observations incite us formulating following proposition as a research perspective for future investigations.

Proposition 2.1: ERP project legitimacy in Thai corporations depends on senior key users involvement

Another key feature is the "flexibility and adjustment orientation" (Joungtrakul, 2006). This flexibility orientation is higher than in western culture in the sense that it determines project acceptance. In ERP implementation, this point worth to be considered is the scope of the project itself concerning supply chain management. This scope determines directly the number modules to be implemented and the integration level of operation management with partners, suppliers and distributors. Three global configuration can be considered in a multi-site ERP implementation (Markus, Tanis, et al., 2000, p. 44):

Total centralisation represents the highest level of integration. All decisions are made by the headquarter and the subsidiaries have to execute. Business units do not have power delegation about their operations with partners and suppliers nor about how the way to manage their intra supply chain.

Headquarter coordination of operations. With this ERP pattern, the headquarter centralises purchases of the subsidiaries via a direct access to their local inventory data and production schedules. Subsidiaries are autonomous in their supply chain management except about suppliers, subcontractors selection and negotiation. From a group perspective, this pattern is interesting into allowing the headquarter to bargain service quality and cost reductions because of common purchasing for whole business entities. 
Network coordination of operations. This configuration represents the lowest "top down" control governance model. Each subsidiary has access to others information about operations and autonomously coordinate their operations. The integration is focused on inter-processes of business units. It is an appropriate configuration for subsidiaries whom the activity is complementary (ex: producer, seller relationships).

The integration level required in an operation total centralisation framework increase the dependency of units. Gilbert and Leclair (2004) reported how in civil engineering project management, ERP implementations change the way main providers (project supervisors, architects, electricians, plumbers, etc.) collaborate. Formerly, they did not have to communicate to other providers the details of calculations on which their analyses were based whereas with the ERP, they became mutual-prescribers. Buddhist culture incites us to be suspicious about potential pervasive effects of such an integration level of Thai subsidiaries with external suppliers. Bunkhun Buddhist principle is related to a long-term orientation of social relationships. In business activity, relations with suppliers, distributors, etc. are constructed over time. While business practices are evolving because of globalisation and western culture influence, Thai managers still remain reluctant to start directly businesses relationships with unknown enterprises. A sort of "acquaintance period" is necessary before being able to consider the relationships as enough trust-based to legitimate business transactions. Face-to-face sustained contacts are preferred to reach this suitable level because allowing the richness of not mediated communications and especially all smile facial expressions which are cultural rites of feeling exchanges (Joungtrakul, 2004). As consequence, empirical research (Niffenegger et al., 2006; Vatanasakdagul et al., 2010) revealed how B2B projects conducted in Thailand were jeopardized because of the reluctance of firms doing business with firms only met online, or disclosing their inventory data to unknown suppliers.

This is incite us to consider, as an additional research perspective, the disruptive effect an ERP project scope can have if it centralises supply chain decisions and mandates business partners to Thai subsidiaries.

Proposition 2.2: ERP project achievement in Thai corporations depends of the scope defined allowing them self-building their relationships with business partners.

\section{Conclusion}

The objective of this article was analysing potential cross-cultural misfits in the case of ERP project implementations. Thailand represents a suitable research field on both economical and cultural aspects. In line with Schein triadic model, we presented ERP as a western cultural artefact likely to induce inconsistent managerial practices with Buddhist basic assumptions and Thai managerial values. However, we tried to go beyond a straightforward description in terms of cultural differences and to analyse how a cross-cultural fit can be reached in IS project management. The research perspectives provided does not cover the endless spectrum of social, philosophical and religious assumptions likely to shape resistances. Moreover, propositions formulated need to be empirically analysed to observe how IT can represent a structuralist object matching western and Thai cultures. However, the article deliberately focused on key points specific to ERP project implementation in terms of change management. While a major part of the literature considers packaged softwares as being conflictual for firms because mandating pre-established managerial processes we developed in this article an alternative approach considering the expected cross-cultural fit as more related to the way ERP project are managed than about the way the systems are designed. We believe this principle as a step toward a "cultural intelligence" (Joungtrakul 2004) in IS project management.

\section{References}

Alavi, M., \& Leidner, D. E. (2001). Review: Knowledge Management and Knowledge Management Systems: Conceptual Foundations and Research Issues. MIS Quarterly, 25(1), 107-136. http://dx.doi.org/10.2307/3250961

Alavi, M., Kayworth, T., \& Leidner, D. E. (2005). An Empirical Examination of the Influence of Organizational Culture on Knowledge Management Practices. Journal of Management Information Systems, 22(3), 191-224. http://dx.doi.org/10.2753/MIS0742-1222220307

Barki, H., \& Hartwick, J. (2001). Interpersonal Conflict and Its Management in Information System Development. MIS Quarterly, 25(2), 195-228. http://dx.doi.org/10.2307/3250929

Beaudry, A., \& Pinsonneault, A. (2005). Understanding User Responses to Information Technology: A Coping Model of User Adaptation. MIS Quarterly, 29(3), 493-524.

Besson, P., \& Rowe, F. (2001). ERP project dynamics and enacted dialogue: Perceived understanding, perceived leeway, and the nature of task-related conflicts. Database for Advances in Information Systems, 32(4), 47-66. http://dx.doi.org/10.1145/506139.506145 
Corbitt, B., Peszynski, K., Inthanond, S., Hill, B., \& Thanasankit, T. (2004). Cultural Differences, Information and Code Systems. Journal of Global Information Management, 3, 65-85. http://dx.doi.org/10.4018/jgim.2004070104

Coser, L. (1956). The Functions of Social Conflict. New York: Free Press.

Davenport, T. H. (1998). Putting the Enterprise into the Enterprise System. Harvard Business Review, 76(4), 121-131.

Drucker, P. (1998). Managing in a time of great change. New York: Dutton/Plume.

Dube, L. (1998). Teams in packaged software development: the software corp. experience. Information Technology \& People, 11(1), 36-61. http://dx.doi.org/10.1108/09593849810204530

El Sawy, O. A. (1985). Implementation by Cultural Infusion: An Approach for Managing the Introduction of Information Technologies. MIS Quarterly, 9(2), 131-140. http://dx.doi.org/10.2307/249114

Ford, J., Ford, L., \& D'Amelio, A. (2008). Resistance to Change: The Rest of the Story. Academy of Management Review, 33(2), 362-377. http://dx.doi.org/10.5465/AMR.2008.31193235

Gilbert, P., \& Leclair, P. (2004). Les systèmes de gestion intégrés. Une modernité en trompe l'œil? Sciences de la société, 61, 17-30.

Gold, A. H., Malhotra, A., \& Segars, A. H. (2001). Knowledge management: An organizational capabilities perspective. Journal of Management Information Systems, 18(1), 185-214.

Handley, K., Sturdy, A., Fincham, R., \& Clark, T. (2006). Within and Beyond Communities of Practice: Making Sense of Learning Through Participation, Identity and Practice. Journal of Management Studies, 43(3), 641-653. http://dx.doi.org/10.1111/j.1467-6486.2006.00605.x

Hart, P., \& Saunders, C. (1997). Power and Trust: Critical factors in the Adoption and use of Electronic Date Interchange. Organization Science, 8(1), 23-42. http://dx.doi.org/10.1287/orsc.8.1.23

Hirschheim, R., \& Newman, M. (1991). Symbolism and Information Systems Development: Myth, Metaphor and Magic. Information Systems Research, 2(1), 29-62. http://dx.doi.org/10.1287/isre.2.1.29

Hoffman, N. (2000). Assimilating new technologies. Information Systems Management, 3, 36.

Hofstede, G. (1991). Culture and organizations: software of the mind. McGraw Hill.

Hofstede, G., \& Bond, M. H. (1988). The Confucius connection: From cultural roots to economic growth. Organizational Dynamics, 16(4), 5-21. http://dx.doi.org/10.1016/0090-2616(88)90009-5

Jarvenpaa, S. L., \& Leidner, D. E. (1998). An Information Company in Mexico: Extending the Resource-Based View of the Firm to a Developing Country. Information Systems Research, 9(4), 342-361. http://dx.doi.org/10.1287/isre.9.4.342

Jasperson, J. S., Carte, T. A., Saunders, C. S., Butler, B. S., Croes, H. J. P., \& Zheng, W. (2002). Review: Power and Information Technology Research: a Metatriangulation Review. MIS Quarterly, 26(4), 397-459. http://dx.doi.org/10.2307/4132315

Jehn, K., \& Weigelt, K. (2001). Reflective versus Expedient Decision Making: Views from Est and West. In Wharton on Making Decision (pp. 103-114).

Joungtrakul, J. (2004). The Cultural Dimensions of Business Management in Thailand. Bangkok.

Joungtrakul, J. (2009). Industrial Democracy and Best Practice in Thailand. Germany: LAP Lambert Academic Publishing.

Kanungo, S., Sadavarti, S., \& Srinivas, Y. (2001). Relating IT strategy and organizational culture: an empirical study of public sector units in India. The Journal of Strategic Information Systems, 10(1), 29-57. http://dx.doi.org/10.1016/S0963-8687(01)00038-5

Kappos, A., \& Rivard, S. (2008). A Three-Perspective Model Of Culture, Information Systems, and Their Development and Use. MIS Quarterly, 32(3), 601-634.

Karahanna, E., Evaristo, J. R., \& Srite, M. (2005). Levels of Culture and Individual Behavior: An Integrative Perspective. Journal of Global Information Management, 13(2), 1-20. http://dx.doi.org/10.4018/jgim.2005040101

Klausner, W. J. (1998). Thai culture in transition. The Siam Society. 
Kohli, R., \& Kettinger, W. J. (2004). Informating the Clan: Controlling Physicians' Costs and Outcomes. MIS Quarterly, 28(3), 363-394.

Komin, S. (1990). The Psychology of the Thai People: Values and Behevioral Patterns. Bangkok: NIDA.

Kwahk, K. Y., \& Lee, J. N. (2008). The role of readiness for change in ERP implementation: Theoretical bases

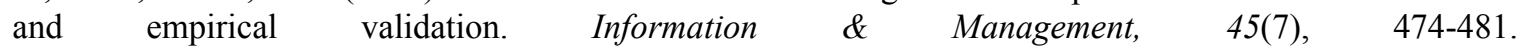
http://dx.doi.org/10.1016/j.im.2008.07.002

Lee, J. C., \& Myers, M. D. (2004). Dominant actors, political agendas, and strategic shifts over time: a critical ethnography of an enterprise systems implementation. The Journal of Strategic Information Systems, 13(4), 355-374. http://dx.doi.org/10.1016/j.jsis.2004.11.005

Leidner, D. E., \& Kayworth, T. (2006). Review: a Review of Culture in Information Systems Research: Toward a Theory of Information Technology Culture Conflict. MIS Quarterly, 30(2), 357-399.

Lim, E. T. K., Shan Ling, P., \& Chee Wee, T. (2005). Managing user acceptance towards Enterprise Resource planning (ERP) systems - understanding the dissonance between user expectations and managerial policies. European Journal of Information Systems, 14(2), 135-149. http://dx.doi.org/10.1057/palgrave.ejis.3000531

Markus, M. L. (1983). Power, Politics, and MIS Implementation. Communications of the ACM, 26(6), 430-444. http://dx.doi.org/10.1145/358141.358148

Markus, M. L. (2000). Paradigm Shifts: E-Business and Business/Systems Integration. Communications of the AIS, 4(10).

Markus, M. L., \& Robey, D. (1983). The Organizational Validity of Management Information Systems. Human Relations, 36(3), 203-226. http://dx.doi.org/10.1177/001872678303600301

Markus, M. L., Axline, S., Petrie, D., \& Tanis, C. (2000). Learning from adopters' experiences with ERP: problems encountered and success achieved. Journal of Information Technology, 15(4), 245-265. http://dx.doi.org/10.1080/02683960010008944

Markus, M. L., Tanis, C., \& Fenema, P. C. van. (2000). Multisite ERP implementations. Communications of the ACM, 43(4), 42-46. http://dx.doi.org/10.1145/332051.332068

McAfee, A. (2007). Mastering the Three Worlds of Information Technology. Harvard Business Review, 141-149.

Meissonier, R., \& Houzé, E. (2010). Toward an 'IT Conflict-Resistance Theory': action research during IT pre-implementation. European Journal of Information Systems, 19(5), 540-561. http://dx.doi.org/10.1057/ejis.2010.35

Newman, M., \& Westrup, C. (2005). Making ERPs work: accountants and the introduction of ERP systems. European Journal of Information Systems, 14(3), 258-272. http://dx.doi.org/10.1057/palgrave.ejis.3000539

Ngwenyama, O. K., \& Nielsen, P. A. (2003). Competing values in software process improvement: an assumption analysis of CMM from an organizational culture perspective. IEEE Transactions on Engineering Management, 50(1), 101-111. http://dx.doi.org/10.1109/TEM.2002.808267

Niffenegger, P., Kulviwat, S., \& Engchanil, N. (2006). Conflicting Cultural Imperatives in Modern Thailand: Global Perspectives. Asia Pacific Business Review, 12(4), 403-420. http://dx.doi.org/10.1080/13602380600571211

Pavlou, P. (2002). Institution-based trust in interorganisational exchange relationships: the role of online B2B marketplaces on trust formation. Journal of Strategic Information Systems, 11, 215-243. http://dx.doi.org/10.1016/S0963-8687(02)00017-3

Ratnasingam, P., \& Phan, D. D. (2003). Trading partner trust in B2B e-commerce: A case study. Information Systems Management, Summer. http://dx.doi.org/10.1201/1078/43205.20.3.20030601/43072.5

Robey, D., \& Markus, M. L. (1984). Rituals In Information System Design. MIS Quarterly, 8(1), 5-15. http://dx.doi.org/10.2307/249240

Robey, D., Ross, J. W., \& Boudreau, M. C. (2002). Learning to Implement Enterprise Systems: An Exploratory Study of the Dialectics of Change. Journal of Management Information Systems, 19(1), 17-46.

Schein, E. H. (1984). Coming to a New Awareness of Organizational Culture. Sloan Management Review, 25(2), 3. 
Shenkar, O., Luo, Y., \& Yeheskel, O. (2008). From 'distance' to 'friction': substituting metaphors and redirecting intercultural research. Academy of Management Review, 33(4), 905-923. http://dx.doi.org/10.5465/AMR.2008.34421999

Soh, C., \& Kien Sia, S. (2004). An institutional perspective on sources of ERP package-organisation

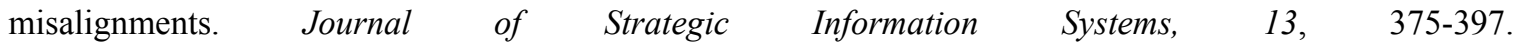
http://dx.doi.org/10.1016/j.jsis.2004.11.001

Straub, D. W. (1994). The Effect of Culture on It Diffusion - E-Mail and Fax in Japan and the United-States. Information Systems Research, 5(1), 23-47. http://dx.doi.org/10.1287/isre.5.1.23

Straub, D. W., Keil, M., \& Brenner, W. (1997). Testing the technology acceptance model across cultures: A three country study. Information \& Management, 33(1), 1-11. http://dx.doi.org/10.1016/S0378-7206(97)00026-8

Strong, D. M., \& Volkoff, O. (2010). Understanding Organization-Enterprise System Fit: a Path to Theorizing the Information Technology Artifact. MIS Quarterly, 34(4), 731-756.

Teece, D. J. (2003). Knowledge and competence as strategic assets. In C. W. Holsapple (Ed.), Handbook on Knowledge Management, Volume 1: Knowledge Matters (pp. 129-152). Heidelberg: Springer- Verlag.

Van Maanen, J., \& Barley, S. (1985). Cultural Organization: Fragments of a Theory. In P. J. Frost, L. F. Moore, M. R. Louis, C. C. Lundberg, and J. Martin (Eds.), Organizational Culture (pp. 31-54). London: Sage.

Vance, A., Elie-Dit-Cosaque, C., \& Straub, D. W. (2008). Examining Trust in Information Technology Artifacts: The Effects of System Quality and Culture. Journal of Management Information Systems, 24(4), 73-100. http://dx.doi.org/10.2753/MIS0742-1222240403

Vatanasakdagul, S., D’Ambra, J., \& Ramburuth, P. (2010). IT Doesn't Fit! The Influence of Culture on B2B in Thailand. Journal of Global Information Technology Management, 13(3), 10-38.

Wagner, E., \& Newell, S. (2004). Best for whom?: the tension between best practice ERP packages and diverse epistemic cultures in a university context. Journal of Strategic Information Systems, 13, 305-328. http://dx.doi.org/10.1016/j.jsis.2004.11.002

Walczuch, R., Lemmink, J., \& Streukens, S. (2007). The effect of service employees' technology readiness on $\begin{array}{llll}\text { technology acceptance. Information \& } & \text { 206-215. }\end{array}$ http://dx.doi.org/10.1016/j.im.2006.12.005

Walsham, G. (2002). Cross-cultural software production and use: A structurational analysis. MIS Quarterly, 26(4), 359-380. http://dx.doi.org/10.2307/4132313

Weber, Y., \& Pliskin, N. (1996). The effects of information systems integration and organizational culture on a $\begin{array}{lllll}\text { firm's effectiveness. Information } \quad \& \quad \text { Management, } & 30(2), & \text { 81-90. }\end{array}$ http://dx.doi.org/10.1016/0378-7206(95)00046-1

Wenger, E., McDermott, R., \& Snyder, W. M. (2002). Cultivating Communities of Practice. Boston: Harvard Business School Press. 